

Journal Chemical Engineering and Industrial Biotechnology (JCEIB) Open Access Volume 3 pp. 87-96; March 2018 (C) Universiti Malaysia Pahang Publisher DOI: https://doi.org/10.15282/JCEIB-V3-09.28/3/2018/3.3

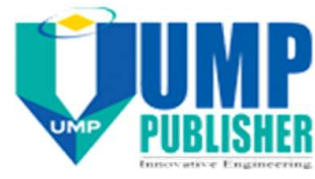

\title{
INVESTIGATION ON PRE-TREATMENT PROCESS IN MICROCRYSTALLINE CELLULOSE (MCC) FROM OIL PALM EMPTY FRUIT BUNCH (EFB)
}

\author{
Muhammad Arif Fahmi Supian ${ }^{\mathrm{a}}$, Khairatun Najwa Mohd Amin ${ }^{\mathrm{a}}$, Saidatul Shima \\ Jamari $^{\mathrm{a}}$, Shahril Mohamad ${ }^{\mathrm{a}}$ \\ ${ }^{a}$ Faculty of Chemical \& Natural Resources Engineering, Universiti Malaysia Pahang, 26300 Gambang, \\ Pahang, Malaysia \\ * Corresponding author: E-mail: knajwa@ump.edu.my \\ Tel.: +609-5492834
}

\begin{abstract}
In this study, microcrystalline cellulose (MCC) was extracted from empty fruit bunch (EFB) with alkaline treatment, bleaching and acid hydrolysis treatment and its properties were compared with commercial MCC. Two conditions were optimized in this study which are fiber consistency and sodium hydroxide $(\mathrm{NaOH})$ concentration in alkaline pretreatment. The obtained optimum consistency and alkaline concentration are 5\% and 20\% respectively. The physicochemical and morphological characteristics, elemental composition and size distribution of the obtained alpha cellulose and MCC were analyzed in this work. Fourier transform infrared spectroscopy (FTIR) analysis provided clear evidence that the characteristic peak of lignin and hemicellulose were absent in the spectrum of the alpha cellulose and MCC. The difference in surface morphology and aggregation between alpha cellulose, MCC and commercialized MCC were observed by scanning electron microscopy (SEM). The mean length of approximately $251.3 \mu \mathrm{m}, 41.4$ $\mu \mathrm{m}$ and $138.6 \mu \mathrm{m}$ were measured for alpha cellulose, MCC and commercialized MCC respectively. Thus, the isolated MCC from EFB has a good potential to be utilized as reinforcing agent in green composites and may be a precursor for future roselle derived nanocellulose, and thus a promising subject in nanocomposite research.
\end{abstract}

Keywords: Empty fruit bunch; microcrystalline cellulose; alpha cellulose; alkaline treatment; .

\subsection{INTRODUCTION}

Malaysia is the world's second-largest palm oil producer and the largest palm oil exporter which consisting of $88 \%$ of the market's palm oil in 2011 (Aghamohammadi et al., 2016). Currently, the largest solid biomass generated in Malaysia originated from oil palm plantations (Farhana Harun et al., 2013). Annually, a minimum of 168 million tonnes of biomass waste is generated in Malaysia. In general, palm oil waste accounts for $94 \%$ of biomass feedstock while the remaining contributors are agricultural and forestry byproducts, such as wood residues $(4 \%)$, rice $(1 \%)$, and sugarcane industry wastes $(1 \%)$ ("Malaysia's biomass potential," 2012). This biomass will assist to solve the waste management but also can create value-added products. Lignocellulosic biomass produced from the oil palm industries including oil palm trunks, oil palm fronds, empty fruit bunch, 
palm pressed fibers, palm shells and palm oil mill effluent (Abdullah \& Sulaiman, 2013).

Most of the agricultural lignocellulosic biomass is comprised of lignin, hemicellulose, and cellulose. Cellulose is a highly stable polymer consisting of glucose and it is majorly composed of (1,4)-D-glucopyranose units (Anwar, Gulfraz, \& Irshad, 2014). Cellulose structure is aligned parallel to each other in fibrils, which are surrounded by a matrix of lignin and hemicellulose. Microcrystalline cellulose (MCC) consist of crystalline structure extract from cellulose. MCC has generated much attention and interest during these few last decades in both academic and industrial fields due to its good properties such as low density, high aspect ratio, stiffness and high strength (Jonoobi, Mathew, \& Oksman, 2012) MCC gained major interest in various applications, such as stabilizer, fat replacer and texturing agent in food industry (Singh, Kanawjia, Giri, \& Khetra, 2015), binder and water retainer in pharmaceutical industry (Johansson \& Alderborn, 2001), and reinforcing agent in plastic industry (Wittaya, 2009).

Currently, the main raw material of cellulose derivative is from wood and cotton linter. However, deforestation and acceleration of greenhouse affect gradually grown interested in agriculture products and by-products as alternative for cellulose resources (Bono et al., 2009). EFB as an oil palm biomass product attracted interest among researcher due to high cellulose content (24-64\%) which has been reported by Chang in 2014 . A few years back, EFB was a valueless biomass produced from the oil palm mill and it will casually be thrown back to the oil palm plantation or burnt in the incinerators for it ash. Furthermore, under this route of disposal, no energy is recovered. According to Abdullah and Sulaim, EFB is a resource which has huge potential to be used for cellulose production which currently not being utilized. In Malaysia, there is no industry that produces MCC. Therefore, the consumer in Malaysia has to import the MCC from outside Malaysia such as China. The demand of MCC had increased from years to years ("Global Microcrystalline Cellulose (MCC) Market: Demand from Cosmetics and Pharmaceuticals Industries to Fuel Demand, says TMR," 2016) .

Cellulose can be extracted from biomass sources via a few pretreatment process which are chemical, biological fermentation, mechanical, physical or mixed processes. Alkali pre-treatment is the most common and important method for delignification of lignocellulosic materials. The main purpose of the pre-treatment is to break down the complex lignocellulosic structure of the biomass by solubilizing the lignin and hemicellulose; increase the porosity and surface area of cellulose and reduce the crystallinity of cellulose (Harmsen et al., 2010). But with the existing research, highly concentrated alkaline solution (40-50\%) was being used. Thus, finding the optimum concentration will greatly save the treatment cost and eventually save the environment from great harm.

Other than that, fiber consistency also plays an important role in the extraction of cellulose. Consistency can be defined as the percentage of weight bone dry fibrous material in any combination of fiber and water. Fiber consistency will affect both the swelling time and swelling degree of the fiber in which both of them will greatly increase the fiber flexibility and strength (Joutsimo \& Asikainen, 2013).

The previous work shows EFB is a potential raw material to produce MCC that have an almost similar characteristic with the commercial MCC which commonly produced from 
wood and cotton (Nasution et al., 2017). Thus, the study on the operable condition in synthetizing the MCC take place by understanding the effect of consistency and $\mathrm{NaOH}$ concentration in the alkaline pre-treatment for the production of MCC from EFB. In this work, the empty fruit bunch are pre-treated using hot water that proceeded by with alkaline pre-treatment using $\mathrm{NaOH}$ and lastly, the $\mathrm{MCC}$ were produced by using hydrolysis process using hydrochloric acid $(\mathrm{HCl})$. The alkaline pre-treatment was optimized by using different concentration of $\mathrm{NaOH}$ solution and the operable condition for the synthesis of MCC was determined by the consistency of the slurry.

\subsection{Materials and Chemical}

\subsection{METHODS AND MATERIALS}

EFB were obtained from LKPP Corporation Sdn. Bhd. palm oil mill, Lepar. Sodium hypochlorite $(\mathrm{NaOCL})$ with purity $10 \%$, sodium hydroxide $(\mathrm{NaOH})$ pallet with purity $98 \%$, hydrochloric acid $(\mathrm{HCl}) 37 \%$, sulphuric acid $\left(\mathrm{H}_{2} \mathrm{SO}_{4}\right)$ with purity $98 \%$ and commercial MCC were purchased from Sigma Aldrich. All the chemicals used were of analytical grade.

\subsection{Sample preparation}

EFB were dried at room temperature for 1 week. Then the EFB was ground using the SIMA grinder model FG 400×200 equipped with $200 \mathrm{~mm}$ mesh.

\subsection{Synthesis of MCC}

\subsubsection{Hot water treatment}

Ground EFB were weight accordingly $(10 \mathrm{~g}, 20 \mathrm{~g}, 50 \mathrm{~g}, 75 \mathrm{~g}$, and $100 \mathrm{~g})$ to obtain different consistency in $1000 \mathrm{ml}$ water. Then the water was heated at $80^{\circ} \mathrm{C}$ for 3 hours and stirred. Hot water treated fibers were washed and dried in oven at $80{ }^{\circ} \mathrm{C}$ overnight.

\subsubsection{Alkaline pre- treatment}

$5 \mathrm{~g}$ of treated EFB was treated with $10 \%$ concentration of sodium hydroxide at $80^{\circ} \mathrm{C}$ for 60 minutes and stirred. The produced alpha cellulose was washed thoroughly with water until it neutralized and dried in oven at $80^{\circ} \mathrm{C}$ overnight. The steps were repeated with $20 \%$ and $40 \% \mathrm{NaOH}$ concentration.

\subsubsection{Bleaching}

Alpha cellulose was bleached at $80^{\circ} \mathrm{C}$ using $100 \mathrm{ml}$ of $2 \%$ sodium hypochlorite $(\mathrm{NaOCl})$ solution for 1 hour. Bleached alpha cellulose was washed and dried in the oven at $80^{\circ} \mathrm{C}$ overnight.

\subsubsection{Acid hydrolysis}

Alpha cellulose was hydrolyzed with $2.5 \mathrm{~N}$ hydrochloric acid at $80^{\circ} \mathrm{C}$ for 15 minutes. The MCC produced was washed thoroughly with water until neutral and dried in oven at $80^{\circ} \mathrm{C}$ overnight. 


\subsection{Characterization}

\subsubsection{Determination of fiber consistency}

Fibers were dried in the oven at $105^{\circ} \mathrm{C}$ for 2 hours before being weight using analytical balance. Formula was used to calculate the consistency of fiber for the synthesis using equation 1.

$$
\frac{\text { oven dry weight of pulp }}{\text { weigh of pulp+water }} \times 100 \%
$$

\subsubsection{Weight loss}

Formula was used to calculate the weight loss using equation 2.

$$
\frac{W_{1}-W_{2}}{W_{1}} \times 100 \%
$$

Where $W_{1}$ is the dry weight before alkaline pre-treatment and $W_{2}$ is the dry weight after alkaline pre-treatment.

\subsubsection{Fourier transform infrared (FTIR).}

The Infrared (IR) spectroscopy were performed on Perkin-Elmer equipment between band 500 to $4000 \mathrm{~cm}^{-1}$. The tests were carried out on the sample of alpha cellulose and MCC.

\subsubsection{Lignin content}

Acid-insoluble lignin content was measured in accordance with TAPPI standard T 222 om-98 "Acid-insoluble Lignin in Wood and Pulp." The moisture content of the sample is determined for air-dried wood/pulp and was used to weigh a known weight of wood/pulp. Concentrated sulphuric acid was utilized to hydrolyze and solubilize the carbohydrates in wood and pulp samples. The acid-insoluble lignin was filtered, dried, and weighed.

\subsubsection{Surface morphology}

Scanning electronic microscopy (SEM) was carried on a Hitachi Tabletop TM3030 Plus under $1-15-\mathrm{kV}$ acceleration voltage was employed to analyze the morphology of alpha cellulose and MCC. Samples were mounted on aluminium stubs with a carbon tape. The average length and diameter of fiber were calculated using Image $\mathrm{J}$ software.

\subsection{Effect of consistency in the pre-treatment process}

The optimization of fiber consistency was done using the Daihan Scientific (MSH-20D) $600 \mathrm{~W}$ hotplate stirrer. Figure 1 shows the graph between consistency and energy (rpm) needed to achieve a homogeneous slurry solution. The consistency has been varied at $1 \%$, $2 \%, 5 \%, 7.5 \%$, and $10 \%$. From the figure, it can be seen that as the energy (rpm) needed to achieve homogeneous proportional to the consistency. But when the consistency of the fiber reaches $10 \%$, the solution cannot achieve a homogeneous solution. It also can be concluded that when the rpm increases the amount of energy needed also increases. From 
the result, that most feasible and applicable consistency is $5 \%$ which showed good agreement with the study reported by Lindsay et.al which mentioned in their study that the best consistency is below than $6 \%$. Thus by using the optimum consistency, a great deal of energy can be saved and $5 \%$ consistency was opted to continue the study.



Figure 1: Effect of consistency (\%) on the rpm needed to achieve a homogeneous slurry

\subsection{Alkaline pre-treatment}

\subsubsection{Effect of $\mathrm{NaOH}$ concentration}

Figure 2 shows the effect of $\mathrm{NaOH}$ concentration used in the alkaline pre-treatment expressed by percent of weight loss. It is shown that significant weight loss increases gradually from $10 \%$ until $20 \%$ of $\mathrm{NaOH}$ and then decrease until $40 \%$ of $\mathrm{NaOH}$. This indicates that the amount of hemicellulose and lignin removal increases gradually with increasing of $\mathrm{NaOH}$ concentration. The extent of hemicellulose and lignin removal reaches the highest value at $20 \% \mathrm{NaOH}$ concentration with $50 \%$ loss in weight and the weight loss percent began to decrease until $40 \% \mathrm{NaOH}$. It can be seen that when the $\mathrm{NaOH}$ concentration is $20 \%$ the weight loss is $50 \%$ and the typical empty fruit bunch hemicellulose and lignin are $35-65 \%$. Thus, it can conclude that almost all of the hemicellulose and lignin were removed in that condition.

TAPPI standard T 222 om-98 "Acid-insoluble Lignin in Wood and Pulp" testing was conducted for the $20 \% \mathrm{NaOH}$ fiber to measure the acid-insoluble lignin content. The result shows that the lignin content in the treated fiber using $20 \% \mathrm{NaOH}$ solution is only $6.5 \%$. The typical lignin content in an empty fruit bunch (EFB) is between $19 \%-20 \%$. It can conclude that $13 \%$ of the lignin has been removed during the alkaline treatment using $20 \% \mathrm{NaOH}$ solution. From both of the result it can be concluded $20 \% \mathrm{NaOH}$ is the best condition of the alkaline pre-treatment with the maximum amount of hemicellulose and 
lignin removal. At the same time to reduce the treatment cost and the impact of the treatment on the environment due to solvent usage.

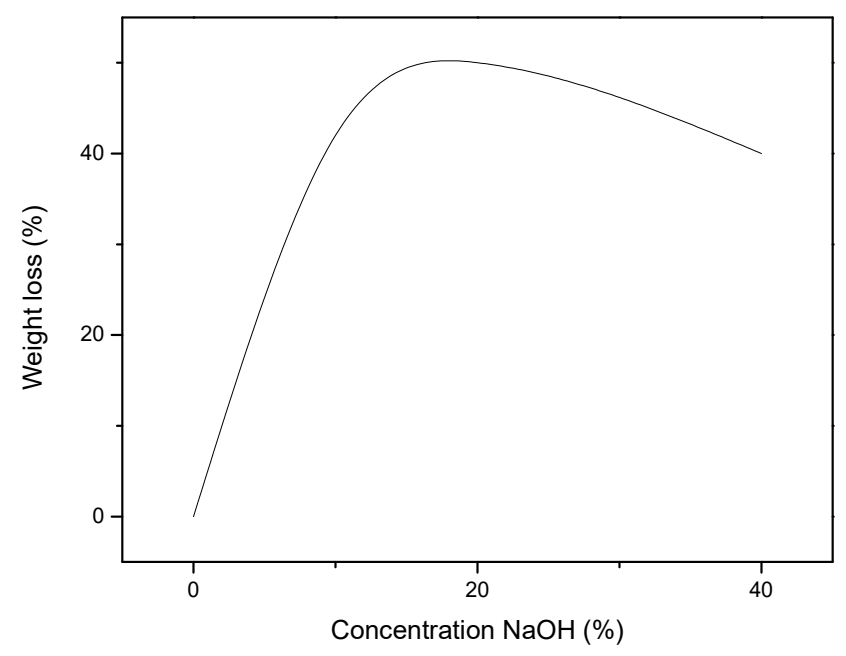

Figure 2: Effect of sodium hydroxide concentration on percent loss in weight

\subsection{Characterization of MCC}

\subsubsection{Surface morphology analysis}

The alpha cellulose and MCC were obtained after bleaching and acid hydrolysis process respectively. Figure 3 shows the morphology of alpha cellulose and MCC under 500X and $2 \mathrm{kX}$ magnification. The SEM micrographs for the alpha cellulose (Figure 3 (A and B), showed a long smooth fibril with the average length $251.3 \mu \mathrm{m}$ and diameter $9.1 \mu \mathrm{m}$. On the other hand, the MCC image shows a crystal-like structure and individualized fiber (Figure 3, C and D) with the average length $41.4 \mu \mathrm{m}$ and diameter $8.3 \mu \mathrm{m}$. Acid hydrolysis led to changes in morphological structure from the fibrillar structure of alpha cellulose to irregular fiber fragments. During the acid hydrolysis, the amorphous structure of the alpha cellulose will be dissolved in the acid leaving the crystalline structure of the alpha cellulose. According to Elanthikkal, Gopalakrishnapanicker, Varghese, \& Guthrie (2010), hydrolysis process penetrates the amorphous regions of alpha cellulose, and cleave the $\beta$-1,4-linkage between the cellulose repeating units, where the alpha cellulose fibers were broken into shorter cellulose, MCC.

For comparison purpose, Figure 3 (E) shows the microstructure of commercial MCC obtained from Sigma Aldrich which extracted from wood. The Figure 3 shows the morphology of commercial MCC is long narrow fibrils strand which is different from the synthesized MCC. The morphology of the synthesized MCC was shorter and less fibril than the commercial MCC that have an average length of $138.6 \mu \mathrm{m}$ and diameter 13.2 $\mu \mathrm{m}$. This indicates that the characteristics of the extracted MCC such as particle sizes and aggregation were influenced by the raw materials and the conditions used during the hydrolysis process (Das et al., 2009) 



Figure 3: SEM micrographs of alpha cellulose (A \& B) and $\mathrm{MCC}(\mathrm{C} \& \mathrm{D})$ at a magnification of $500 \mathrm{X}$ and $2 \mathrm{kX}$; and $(\mathrm{E})$ commercial MCC at magnification $500 \mathrm{x}$

(Xiang et al., 2016)

\subsubsection{Fourier transforms infrared}

FTIR spectra of alpha cellulose and MCC were recorded in the range of 4000-500 $\mathrm{cm}^{-1}$. Figure 4 shows the stretching vibration of $\mathrm{OH}$ group (3200 to $\left.3400 \mathrm{~cm}^{-1}\right), \mathrm{C}-\mathrm{H}$ group $\left(2886 \mathrm{~cm}^{-1}\right)$, O-H bending $\left(1657 \mathrm{~cm}^{-1}\right), \mathrm{C}-\mathrm{O}-\mathrm{C}$ stretching $\left(1029 \mathrm{~cm}^{-1}\right)$ and the $\beta-$ glucosidic (896 cm-1) (Khalil et al., 2001; Nacos et al., 2006). The dif transmittance for hydroxyl $(-\mathrm{OH})$ group is represents by wavenumber around $3300 \mathrm{~cm}^{-1}$ which existed for MCC and alpha cellulose. The broadening was attributed to the presence of amorphous fraction of the cellulose. This was due to the degradation of the hydrogen bond between the cellulosic chains during the hydrolysis process (Nasution et al., 2017) and indicating that the hydrolysis process weakened the hydrogen bonding of cellulose (Zhang, Ren, \& $\mathrm{Li}, 2013)$. However, the peak of MCC is slightly broader, than alpha cellulose due to the increase of hydroxyl group on the surface of MCC after acid hydrolysis on cellulose. The infrared spectroscopy shows that the acid hydrolysis reaction performed to obtain MCC 
does not affect the main chemical structure of the cellulosic fragments. It means that acid hydrolysis of alpha cellulose did not affect the cellulosic components.

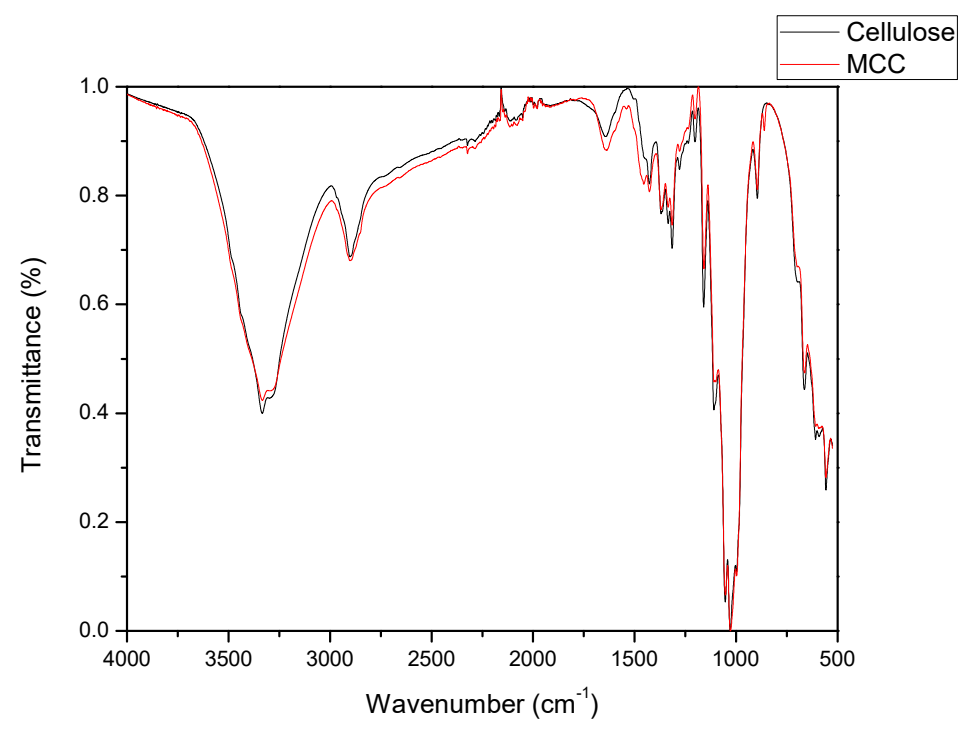

Figure 4: Fourier Transform Infrared (FTIR) spectra of the obtained alpha cellulose and microcrystalline cellulose (MCC)

\subsection{CONCLUSION}

MCC has been successfully synthesized from EFB. The most suitable fiber pulp consistency for the synthesis of microcrystalline cellulose was 5\%. This study showed that alkaline pre-treatment at $20 \%$ of $\mathrm{NaOH}$ concentration gave the best result. $\mathrm{MCC}$ was prepared by hydrolysis acid using hydrochloric acid $(2.5 \mathrm{~N})$. The results obtained from FTIR analysis confirmed that chemical structure of the cellulosic fragments is not influenced by the acid hydrolysis and SEM shows that the MCC has a rough and compact structure, similar to the commercial MCC, although it exhibits much smaller fragments.

\section{ACKNOWLEDGEMENT}

The authors would like to thank financial support from grants (RDU1603128 and UIC171004) funded by Universiti Malaysia Pahang, lecturers of Faculty of Chemical \& Natural Resources Engineering and LCSB company for their supports.

\section{REFERENCES}

Awalludin, M. F., Sulaiman, O., Hashim, R., \& A. W. Nadhari, W. N. (2015). An overview of the oil palm industry in Malaysia and its waste utilization through thermochemical conversion, specifically via liquefaction. Renewable and Sustainable Energy Reviews, (50), 1469-1484. 3

Abdullah, N., \& Sulaiman, F. (2013). The oil palm wastes in Malaysia. Biomass Now - Sustainable Growth and Use, 3, 75-100.

Aghamohammadi, N., Reginald, S. S., Shamiri, A., Zinatizadeh, A. A., Wong, L. P., \& Binti Nik Sulaiman, N. M. (2016). An investigation of sustainable power generation from oil palm biomass: a case study in sarawak. Sustainability, 8, 119.

Ambjörnsson, H. A., Schenzel, K., \& Germgård, U. (2013). Microcrystalline cellulose produced at different mercerization condition and caracterized by nir $\mathrm{ft}$ raman spectroscopy in combination with multivariate analytical methods. BioResources, 8(2), 1918-1932.

Anwar, Z., Gulfraz, M., \& Irshad, M. (2014). Agro-industrial lignocellulosic biomass akey to unlock the 
future bio-energy: A brief review. Journal of Radiation Research and Applied Sciences, 7(2), 163173.

Bono, A., Ying, P. H., Yan, F. Y., Muei, C. L., Sarbatly, R., \& Krishnaiah, D. (2009). Synthesis and characterization of microcrystalline cellulose from palm kernel cake. Advances in Natural and Applied Sciences, 3(1), 5-11.

Chang, S. H. (2014). An overview of empty fruit bunch from oil palm as feedstock for bio-oil production. Biomass and Bioenergy, 62, 174-181. doi:10.1016/j.biombioe.2014.01.002

Chuayjuljit, S., Su-uthai, S., \& Charuchinda, S. (2010). Poly(vinyl chloride) film filled with microcrystalline cellulose prepared from cotton fabric waste: properties and biodegradability study. Waste Management \& Research, 28(2), 109-117. doi:10.1177/0734242x09339324

Das, K., Ray, D., Bandyopadhyay, N. R., Ghosh, T., Mohanty, A. K., \& Misra, M. (2009). A study of the mechanical, thermal and morphological properties of microcrystalline cellulose particles prepared from cotton slivers using different acid concentrations. Cellulose, 16(5), 783-793. doi:10.1007/s10570-009-9280-6

Elanthikkal, S., Gopalakrishnapanicker, U., Varghese, S., \& Guthrie, J. T. (2010). Cellulose microfibers produced from banana plant wastes: Isolation and characterization. Carbohydrate Polymers, 80(3), 852-859. doi:10.1016/j.carbpol.2009.12.043

Embrandiri, A., Ibrahim, M. H., \& Singh, R. P. (2013). Palm oil mill waste utilization; sustainability in the malaysian context. International Journal of Scientific and Research Publications, 3(3), 1-7.

Farhana Harun, N. A., Baharuddin, A. S., Mohd Zainuddin, M. H., Bahrin, E. K., Naim, M. N., \& Zakaria, R. (2013). Cellulose production from treated oil palm empty fruit bunch degradation by locally isolated thermobifida fusca. BioResource, 8(1), 676-687.

Global Microcrystalline Cellulose (MCC) Market: Demand from Cosmetics and Pharmaceuticals Industries to Fuel Demand, says TMR. (2016, November). Retrieved from https://www.transparencymarketresearch.com/pressrelease/microcrystalline-cellulose-marketsize.htm

Gunstone, F. (2011). ed. Vegetable Oils in Food Technology: Composition, properties and Uses. $2^{\text {nd }}$ Edition. Electronic book: Blackwell Publishing.

Haafiz, M. M., Hassan, A., Zakaria, Z., Inuwa, I., Islam, M., \& Jawaid, M. (2013). Properties of polylactic acid composites reinforced with oil palm biomass microcrystalline cellulose. Carbohydrate Polymers, 98(1), 139-145. doi:10.1016/j.carbpol.2013.05.069

Hong, L. S., Ibrahim, D., \& Omar, I. C. (2012). Oil palm frond for the production of bioethanol. International Journal of Biochemistry and Biotechnology, 1(1), 007-011.

Iberahim, N. I., Jahim, J. M., Harun, S., Nor, M. T., \& Hassan, O. (2013). Sodium Hydroxide Pretreatment and Enzymatic Hydrolysis of Oil Palm Mesocarp Fiber. International Journal of Chemical Engineering and Applications, 101-105. doi:10.7763/ijcea.2013.v4.272

Ibrahim, S. M., Badri, K. H., \& Hassan, O. (2012). A study on glycerolysis of oil palm empty fruit bunch fiber. Sains Malaysiana, 41(12), 1579-1585.

Jonoobi, M., Mathew, A. P., \& Oksman, K. (2012). Producing low-cost cellulose nanofiber from sludge as new source of raw materials. Industrial Crops and Products, 40, 232-238. doi:10.1016/j.indcrop.2012.03.018

Johansson, B., \& Alderborn, G. (2001). The effect of shape and porosity on the compression behaviour and tablet forming ability of granular materials formed from microcrystalline cellulose. European Journal of Pharmaceutics and Biopharmaceutics, 52(3), 347-357. doi:10.1016/s09396411(01)00186-2

Joutsimo, O. P., \& Asikainen, S. (2013). Effect of Fiber Wall Pore Structure on Pulp Sheet Density of Softwood Kraft Pulp Fibers. BioResources, 8(2). doi:10.15376/biores.8.2.2719-2737

Khalil, H., Ismail, H., Rozman, H., \& Ahmad, M. (2001). The effect of acetylation on interfacial shear strength between plant fibres and various matrices. European Polymer Journal, 37(5), 1037-1045. doi:10.1016/s0014-3057(00)00199-3

Lindsay, J. D., \& Gullichsen, J. (1994). Pulp pulping and hydraulics. Institude of Paper Science and Technology.

Mahlia, T., Abdulmuin, M., Alamsyah, T., \& Mukhlishien, D. (2001). An alternative energy source from palm wastes industry for Malaysia and Indonesia. Energy Conversion and Management, 42(18), 2109-2118. doi:10.1016/s0196-8904(00)00166-7

Nasution, H., Yurnaliza, Veronicha, Irmadani, \& Sitompul, S. (2017). Preparation and Characterization of Cellulose Microcrystalline (MCC) from Fiber of Empty Fruit Bunch Palm Oil. IOP Conference Series: Materials Science and Engineering, 180, 012007. doi:10.1088/1757-899x/180/1/012007

Ramli, R., Junaidi, N., H. Beg, M. D., \& Yunus, R. M. (2015). Microcrystalline cellulose frim oil palm 
empty fruit buch fiber via simultaneous ultrasonic and alkaline treatment. International Journal of Chemical, Molecular, Nuclear, Materials and Metallurgical Engineering, 9(1), 8-11.

R. Emmyrafedziawati, A. K., \& Stella, M. (n.d.). Hydrolysis of microcrystalline cellulose (mcc) by bacillus isolated from compost. J. Trop. Agric. and Fd. Sc, 43(2), 129-135.

Rushdan, I., Latifah, J., Hoi, W. K., \& M. Nor, M. Y. (2007). Commercial-scale production of soda pulp and medium paper from oil palm empty fruit bunch. Journal of Tropical Forest Science, 19(3), 121-126.

Soom, R. M., Wan Hassan, W. H., Md Top, A. G., \& Hassan, K. (2006). Thermal properties of oil palm fibre, cellulose and its derivatives. Journal Of Oil Palm Reasearch, 18, 272-277.

Singh, M., Kanawjia, S., Giri, A., \& Khetra, Y. (2014). Effect of Temperature and Microcrystalline Cellulose on Moisture Sorption Characteristics of Shredded Mozzarella Cheese. Journal of Food Processing and Preservation, 39(5), 521-529. doi:10.1111/jfpp.12257

Thoorens, G., Krier, F., Leclercq, B., Carlin, B., \& Evrard, B. (2014). Microcrystalline cellulose, a direct compression binder in a quality by design environment-A review. International Journal of Pharmaceutics, 473(1-2), 64-72. doi:10.1016/j.ijpharm.2014.06.055

Wittaya, T. (2009). Microcomposites of rice starch film reinforced with microcrystalline cellulose from palm pressed fiber. International Food Research Journal, 16(4), 493-500.

Xiang, L. Y., P. Mohammed, M. A., \& Samsu Baharuddin, A. (2016). Characterisation of microcrystalline cellulose from oil palm fibres for food applications. Carbohydrate Polymers, 148, 11-20. doi:10.1016/j.carbpol.2016.04.055

Zhang, F., Ren, H. W., \& Li, J. P. (2013). Study of the Structural Properties of Microcrystalline Cellulose (MCC) Particles from Distillers Grains (DG) by XRD, FTIR and SEM. Applied Mechanics and Materials, 295-298, 339-344. doi:10.4028/www.scientific.net/amm.295-298.339.

http://www.chem.qmul.ac.uk/iubmb/enzyme. 